\title{
Agricultural ecosystem management in dry areas: challenges and solutions
}

\author{
Neil C. Turner • Feng-Min Li • You-Cai Xiong • \\ Kadambot H. M. Siddique
}

Published online: 7 September 2011

(C) Springer Science+Business Media B.V. 2011

Agricultural ecosystem sustainability and plant-soil interactions in arid and semiarid regions have received increasing interest by research scientists and policy makers over recent decades (Liang et al. 2010; WMO 2005). Globally 54 million $\mathrm{km}^{2}$ or 40 per cent of the land area is occupied by drylands, with about $30 \%$ of this area being arid, $44 \%$ semiarid, and $26 \%$ in the dry sub-humid zone (WMO 2005). With 34\% and $15 \%$ of the drylands being located in Asia and Australia, respectively, the arid and semiarid areas of China and Australia represent important examples of the challenges to and opportunities for agroecological sustainability of these regions worldwide. While important for sources of food, feed and fibre,

Responsible Editor: Hans Lambers.

N. C. Turner $(\bowtie)$

Centre for Legumes in Mediterranean Agriculture, M080,

The University of Western Australia,

35 Stirling Highway,

Crawley, WA 6009, Australia

e-mail: neil.turner@uwa.edu.au

N. C. Turner $\cdot$ K. H. M. Siddique

The UWA Institute of Agriculture, M082,

The University of Western Australia,

35 Stirling Highway,

Crawley, WA 6009, Australia

F.-M. Li • Y.-C. Xiong

Ministry of Education Key Laboratory of Arid

and Grassland Ecology, Department of Arid Agoecology,

School of Life Sciences, Lanzhou University,

Lanzhou 730000 Gansu Province, China semiarid regions of the world are subject to water shortages and soil degradation that are likely to increase with climate change (Turner and Meyer 2011; WMO 2005). In semiarid regions of northwest China and south-west Australia, water scarcity, a lack water and infrastructure for irrigation, a drying climate and greater intensity storms pose a challenge to food security and environmental sustainability ( $\mathrm{Li}$ 1999; Shangguan et al. 1999; Liang et al. 2010; Wang et al. 2010; Turner and Meyer 2011; Turner et al. 2011). A variety of problems frequently occur on the nutrient-poor, fragile soils in these regions (Douglas 1989; Meng 1996; Zheng 1996; Li 1999; Wang et al. 2008; Liang et al. 2010; Turner et al. 2011; Shi et al. 2011; Yamaguchi 2011). The solutions are expected to come from the integrated investigation of plant and soil interactions at a range of scales from the individual plant to field and catchment level to the whole region.

North-west China is a vast region with two major plateaus, the Loess Plateau and the Qinghai-Tibetan Plateau (Fig. 1). The Loess Plateau covers $640,000 \mathrm{~km}^{2}$ in seven provinces - Gansu, Henan, Inner Mongolia, Ningxia, Qinghai, Shanxi and Shaanxi-and supports a population of 34 million people. The section of the Loess Plateau in Inner Mongolia is contiguous with the Mongolian Plateau and is sometimes referred to as the Inner Mongolian Plateau (Zhang et al. 2011). With an average height of $1200 \mathrm{~m}$ above sea level, the Loess Plateau has a monsoonal continental climate with cold dry winters and warm wet summers. Annual mean 


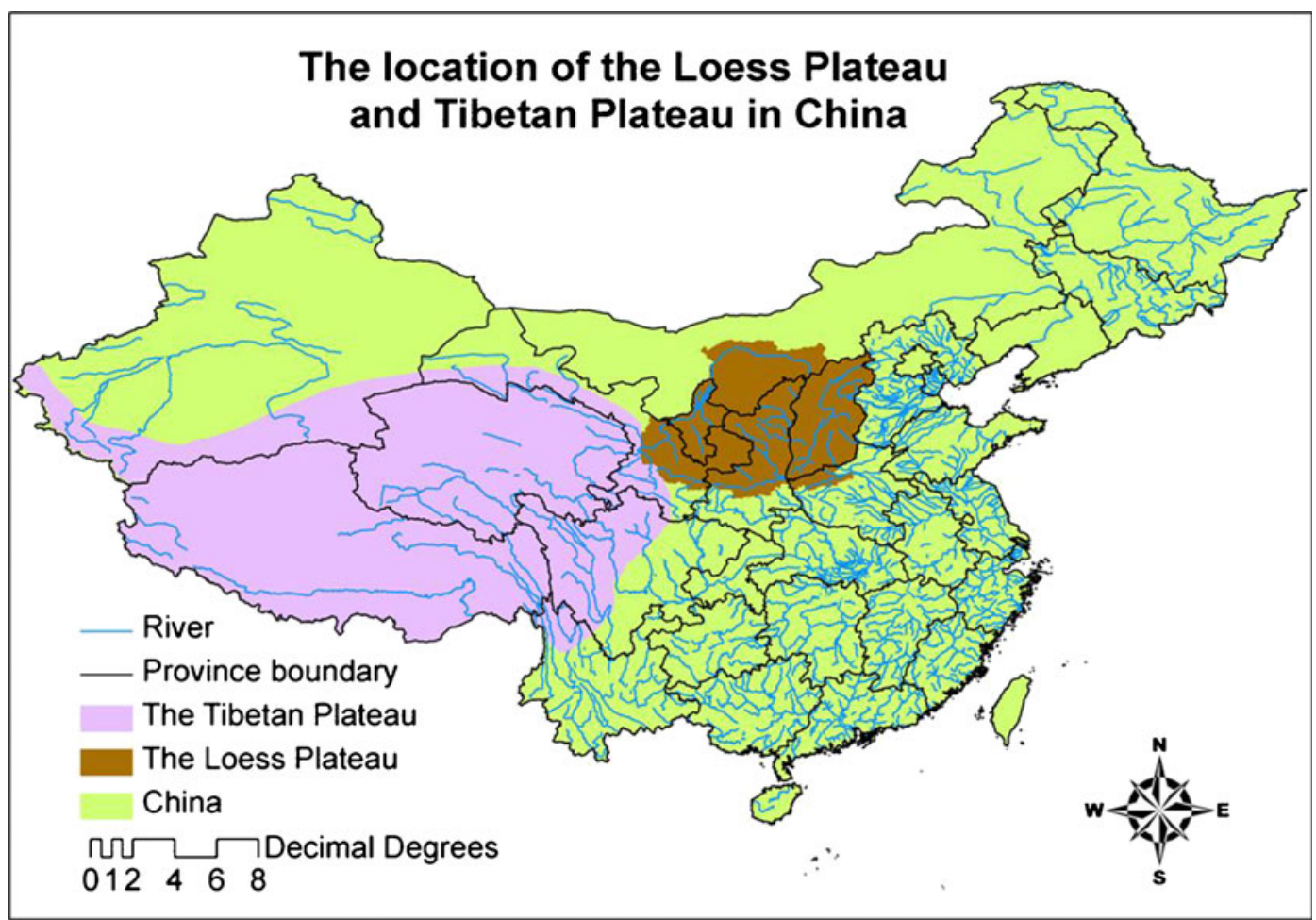

Fig. 1 Map of China with the Loess Plateau (brown) and Qinghai-Tibetan Plateau (purple) highlighted

temperatures vary from just below $0^{\circ} \mathrm{C}$ in the higher west of the Plateau to just above $20^{\circ} \mathrm{C}$ in the south, but the majority of the Loess Plateau has a mean temperature of about $10^{\circ} \mathrm{C}$ (Turner et al. 2011). Annual rainfall varies from about $600 \mathrm{~mm}$ in the south to between 100 and $200 \mathrm{~mm}$ in the north-west (Turner et al. 2011). The wind-blown, silty soil, which generally is 50 to $80 \mathrm{~m}$ deep, has a high water-holding capacity (about $26 \%$ at field capacity), but is very vulnerable to water erosion, resulting in a highly-dissected, fragile landscape (Fig. 2). With 1.6 billion tons of soil being lost by erosion annually, the Loess Plateau is regarded as one of the most severely eroded and eroding areas in the world with important ecological and socioeconomic consequences (Liu 1985; Douglas 1989; Saito et al. 2001; Wang et al. 2010). Nevertheless, the Loess Plateau is an important dryland agricultural area providing food security and employment for a greater population than its 34 million residents. Of the total area of 64 million hectares $\left(640,000 \mathrm{~km}^{2}\right)$, about 15 million hectares is cultivated and half of this cultivated area is sloping land (Shangguan et al. 1999) that is very vulnerable to water and wind erosion as a consequence of deforestation and overgrazing. The
Qinghai-Tibetan Plateau is the largest plateau in the world, covering approximately 2.5 million $\mathrm{km}^{2}$ (Zheng 1996) with an average altitude of more than $4000 \mathrm{~m}$ above sea level. It is located south west of the Loess Plateau and stretches to the Chinese border with India and Nepal (Fig. 1). The Qinghai-Tibetan Plateau provides natural free-grazing for the yaks, cattle and sheep of livestock farmers who take their animals to graze on alpine pastures above $4000 \mathrm{~m}$ in the warmer summer months after the snow has melted. Overgrazing and consequent erosion is becoming a major issue, particularly at lower elevations where the animals overwinter (Wang et al. 2008; Yamaguchi 2011). Crops are not a feature in this landscape, but some fodder crops are grown at lower elevations.

South-west Australia has similar rainfall to the Loess Plateau, but predominantly during the winter growing season, as opposed to the summer rainfall pattern and growing season of the Loess Plateau (Turner et al. 2011). More than two thirds of the soils in south-west Australia are deep sands and sands over clay (Turner 1992), subject to wind and water erosion, transient waterlogging and secondary salinity (Turner 1992, 2004). In both China and Australia, the ability 


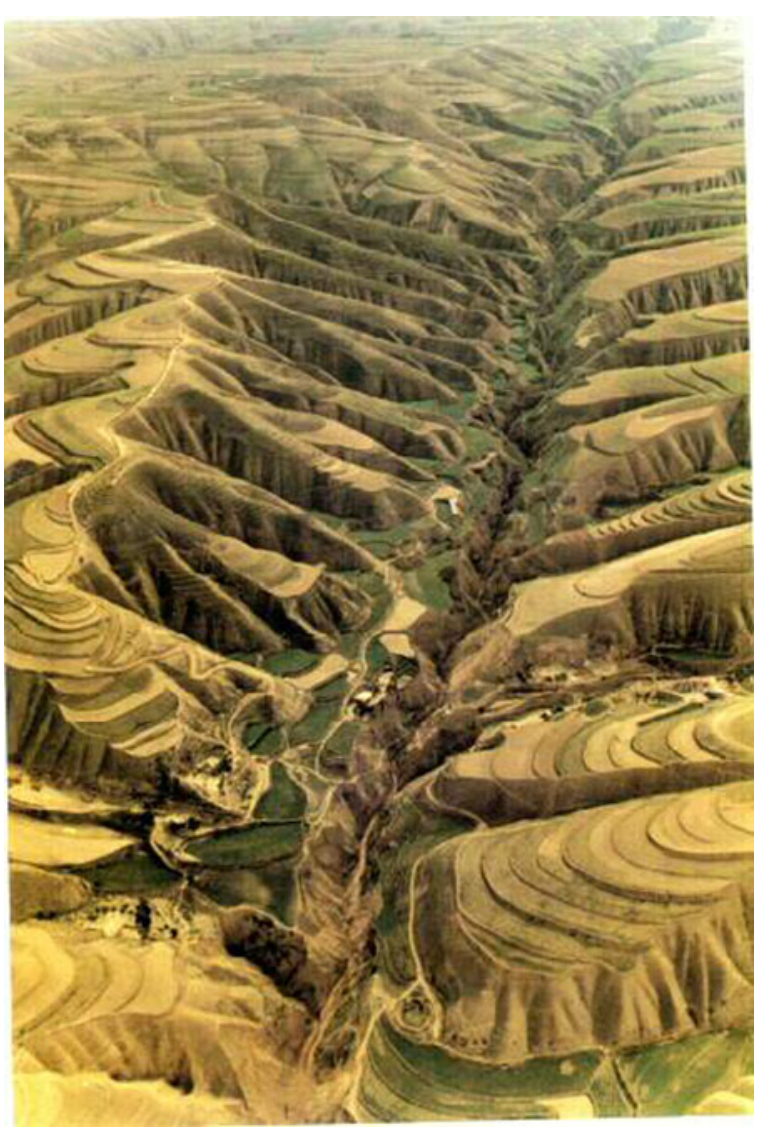

Fig. 2 Aerial photograph of part of the Loess Plateau showing marked erosion and terracing to stabilise the slopes. (Photo courtesy of Dr Xiping Deng, Institute of Soil and Water Conservation, Yangling, Shaanxi, China)

to build up and maintain organic matter is important for both soil stability, plant productivity and carbon sequestration.

In order to address common issues of maintaining agricultural productivity and ecosystem services in fragile ecosystems, the 2nd International Workshop on Ecological Assessment and Management with the theme "Climate change and agricultural ecosystem management in dry areas", was held in Lanzhou, Gansu Province, China, from 20 to 25 July 2010. The workshop was organised by the Ministry of Education Key Laboratory of Arid and Grassland Ecology, Department of Arid Agoecology at Lanzhou University and the UWA Institute of Agriculture at the University of Western Australia, Perth, Australia, and included leading scientists from China, Australia, the United States of America, Canada, Syria and Japan. This issue of Plant and Soil publishes six selected papers addressing ecological sustainability of agricultural and natural ecosystems following peer-review. Other papers presented at the workshop have been published in special issues of Acta Ecologica Sinica (volume 31, number 9, pages 2349-2654, 2011-in Chinese with English abstracts), Crop and Pasture Science (Volume 62, Issue 6, pages 445-503, 2011) and Functional Plant Biology (Palta et al. 2011).

The papers selected from the workshop for publication in Plant and Soil focus on agricultural ecosystem management of plant-soil interaction in dry areas on the scale of individual plants, plants in community to plants on a regional scale. Wheat (Triticum aestivum), maize (Zea mays) and typical fodder species are used in the papers to illustrate the eco-physiological responses and related management strategies. The two dryland crops grown extensively on the Loess Plateau are wheat, both spring and winter genotypes, and maize (Turner et al. 2011). Landraces of wheat are grown on the Loess Plateau for their superior noodle quality, but Fang et al. (2011) demonstrate that a landrace of winter wheat, while showing better competitive ability with adequate water availability than a modern cultivar, used more water prior to flowering and was more sensitive to water shortage after flowering so that it was less competitive than a modern cultivar under restricted water supply. Yields and yield stability were greater in the modern cultivar of winter wheat than the landrace under water limitation in the glasshouse and in the field in two years when precipitation was below the long-term mean (Fang et al. 2011). It is notable that grain production in China has increased almost linearly since 1949 (Zhang 2011), particularly wheat yields that have increased at a rate of $88 \mathrm{~kg} \mathrm{ha}^{-1} \mathrm{y}^{-1}$ from 1960 to 2009 (Turner et al. 2011). While this cannot be attributed entirely to the increased use of fertilizer (Zhang 2011), Lefroy (2008) clearly demonstrated that the change in net food production among different regions of the world was strongly associated with fertilizer use. China was shown to be the country with both the highest fertilizer use and the greatest change in net food production (Lefroy 2008). However, there are concerns that in a water-limited environment, such as north-west China, the increased use of fertilizers, will increase growth and consequently increase water use, thereby reducing the availability of water for the following crop in the cropping sequence, especially in below average 
rainfall years. In a long-term experiment, Wang et al (2011) showed that after 20 to 25 years of application of $120 \mathrm{~kg} \mathrm{ha}^{-1}$ of nitrogen as urea and $60 \mathrm{~kg} \mathrm{ha}^{-1}$ of phosphorus $\left(\mathrm{P}_{2} \mathrm{O}_{5}\right)$ as superphosphate, with and without farmyard manure, water use of winter wheat increased by $23 \%$ over that in the unfertilized check. However, the soil water recharge in the fallow period also increased, so that the soil water content did not decrease even though yields of wheat during the four years of measurement were more than double those in the unfertilized treatment. This suggests that continuous wheat production is sustainable on the Loess Plateau with good management, including high but appropriate inputs of inorganic fertilizers. While wheat and maize straw is usually harvested for animal feed (cut and carry system) in China, some crop residues are returned to the soil through roots and leaf litter, and these will be higher when yields are higher as a result of the application of inorganic fertilizers.

Although application of inorganic fertilizers benefitted yields of wheat in the absence of manure, manure produced by penned animals is often applied by small-holder farmers to crops on the Loess Plateau, resulting in an increase in the soil organic matter that benefits the soil structure, infiltration and water-holding capacity of the soil (Wu et al. 2004; Yang et al. 2006). In the extensive farming system in south-west Australia, animal manures are not applied, and farmers rely on rotation with legumes, such as field pea (Pisum sativum), narrow-leaved lupin (Lupinus angustifolius), a variety of pasture legumes, and rotation with canola (Brassica napus), to enable grass weed and disease management, to provide a source of organic legume nitrogen and to add crop residues to the soil to maintain the soil organic matter (Turner et al. 2011). Hoyle and Murphy (2011) show that lupin and field pea residues increased the amounts of plant-available nitrogen compared with oats (Avena sativa), particularly where the crops were not harvested, but ploughed in as a brown manure after desiccation with herbicide application, and this had a significant effect on the yield of a subsequent wheat crop. While incorporation of crop residues proved very beneficial, the amount of nitrogen available to the subsequent wheat crop varied markedly with time, with nitrate nitrogen being influenced by the wet-dry cycles and the level of incorporation of residues, with the highest concentrations just before and shortly after sowing (Hoyle and Murphy 2011).
Only $25 \%$ of the area of the 64 million hectares of the Loess Plateau is cultivated. Of the remaining $75 \%$, half comprises natural grassland on which Lespedeza davurica and Bothriochloa ischaemum are the two codominant species, and are important in reducing and preventing soil erosion. L. davurica is a $\mathrm{C}_{3}$ leguminous shrub while $B$. ischaemum is a $\mathrm{C}_{4}$ perennial grass. Xu et al. (2011) show that B. ischaemum is much more aggressive and competitive than $L$. davurica in all levels of water availability, but with water scarcity the competitive ability of $L$. davurica increased relative to $B$. ischaemum. The values of relative total yield indicated that there was some resource complementarity even with low water availability and that it was advantageous to grow the two species together to maximise production and precipitation use efficiency in water-limited situations. Shrubs in arid and semiarid regions also play a role in creating islands of fertility as they collect windblown sand and litter, increase infiltration and enable deeper penetration of water into the soil (Bhark and Small 2003). Zhang et al. (2011) studied Caragana tibetica, a small perennial shrub of desert communities on the northern part of the Loess Plateau in Inner Mongolia. They show that the shrub entraps fine sand, and develops fertile areas with increased soil organic matter, nutrients and water in the resultant mound, called a "nebkha", created by the collection of sand under and by the side of the shrub. C. tibetica shrubs are therefore important in reducing erosion and maintaining soil stability in the dry desert region of the Loess Plateau. However, they do not appear to accumulate sufficient water to enable herbaceous species to become established.

While $C$. tibetica is clearly beneficial in stabilising the soil and developing areas of fertility in arid and semiarid areas, Ligularia virgaurea is a perennial herb that is becoming the dominant species in the heavilygrazed montane pastures of the Qinghai-Tibetan Plateau. It is poisonous to stock, has high reproductive success and an efficient dispersal system, and it is these characteristics that are thought to be responsible for its successful dominant role in overgrazed pastures where it is replacing palatable species. However, Shi et al. (2011) suggest that it is the heightened fertility under patches of $L$. virgaurea that allow it to capitalize on its unpalatability, vigorous growth and reproductive characteristics to dominate the pastures. Their studies show that in the surface soil $L$. virgaurea 
increased root biomass, total soil organic carbon and phosphorus concentrations, carbon and nitrogen mineralization, and the concentration of carbon and nitrogen in the microbial biomass compared with those measured under other pasture species. $L$. virgaurea lowered the concentration of nitrate nitrogen in the surface soil, depriving competitors of nitrogen in this nitrogen-limited environment and thereby increasing the competitive ability of the toxic weed (Shi et al. 2011).

Thus competitive ability, that is competition for water and/or nutrients, has been one of the major themes of the six following papers in this special issue. The papers, together with those published in Acta Ecologica Sinica, Crop and Pasture Science and Functional Plant Biology demonstrate the rich diversity of research being conducted to improve agricultural ecosystem management in the world's dryland agricultural ecosystems. While climate change was not a major theme in the papers in this special issue, adaptation to climate change was a major theme of the workshop (Turner et al. 2011) and highlighted the need for future solutions to be developed that integrate studies of crops, animals and soils, couple water and nutrient relations, and link regional ecosystem assessment with management.

Acknowledgements We thank The University of Western Australia, MOE Key Laboratory of Arid and Grassland Ecology of Lanzhou University, the International Centre for Agricultural Research in Dry Areas, the National Basic Research Program of China ("973" Project) (2007CB106804 and 2009CB825101), the "111" Program of the State Administration of Foreign Experts Affairs and the Ministry of Education of China for financial support. The assistance of the Managing Editors at Plant and Soil in the review and publication of the papers in this special issue is gratefully acknowledged.

\section{References}

Bhark EW, Small EE (2003) Association between plant canopies and the spatial patterns of infiltration in shrubland and grassland of the Chihuahuan desert, New Mexico. Ecosystems 6:185-196. doi:10.1007/s10021-002-0210-9

Douglas I (1989) Land degradation, soil conservation and the sediment load of the Yellow River, China: review and assessment. Land Degrad Dev 1:141-151

Fang Y, Liu L, Xu B-C, Li F-M (2011) The relationship between competitive ability and yield stability in an old and a modern winter wheat cultivar. Plant Soil 347:7-23

Hoyle FC, Murphy DV (2011) Influence of organic residues and soil incorporation on temporal measures of microbial biomass and plant available nitrogen. Plant Soil 347:53-64
Lefroy RDB (2008) Australian agronomy abroad. In: Unkovich MF (ed) Global issues paddock action. Proceedings of the 14th Australian Agronomy Conference, September 2008, Adelaide, South Australia. www.regional.org.au/au/asa/ 2008/plenary/agronomy-abroad/5942_lefroyrdb.

Li FM (1999) On agricultural productivity and ecosystem's sustainability in semiarid areas of China. Resour Sci 21:25-30. doi:cnki:ISSN:1007-7588.0.1999-05-003, in Chinese with English abstract

Liang Y, Zhu YG, Smith FA, Lambers H (2010) Soil-plant interaction and sustainability of eco-agriculture in arid region: a crucially important topic to address. Plant Soil 326:1-2. doi:10.1007/s11104-009-0208-6

Liu DS (1985) Loess and the environment. China Ocean Press, Beijing, pp 400-413, published in Chinese

Meng QM (1996) Water and soil conservation on the Loess Plateau. Yellow River Conservancy Press, Zhengzhou, pp 56-67, published in Chinese

Palta JA, Chen X, Milroy SP, Rebetzke GJ, Dreccer MF, Watt M (2011) Large root systems: are they useful in adapting wheat to dry environments? Funct Plant Biol 38:347-354. doi:10.1071/FP11031

Saito Y, Yang ZS, Hori K (2001) The Huanghe (Yellow River) and Changjiang (Yangtze River) deltas: a review on their characteristics, evolution and sediment discharge during the holocene. Geomorphol 41:219-231. doi:10.1016/ S0169-555X(01)00118-0

Shangguan Z, Peng K, Peng L, Wang L (1999) Grain production and sustainable development in the Loess Plateau. Shaanxi People's Publishing Press, Xi'an, Chinese with English abstract

Shi XM, Li XG, Wu RM, Yang YH, Long RJ (2011) Changes in soil biochemical properties associated with Ligularia vigaurea spreading in grazed alpine meadows. Plant Soil 347:65-78

Turner NC (1992) Crop production on duplex soils: an introduction. Aust J Exp Agric 32:797-800

Turner NC (2004) Sustainable production of crops and pastures under drought in a Mediterranean environment. Ann Appl Biol 144:139-147

Turner NC, Meyer R (2011) Synthesis of regional impacts and global agricultural adjustments. In: Yadav SS, Redden R, Hatfield JL, Lotze-Campen H, Hall A (eds) Crop adaptation to climate change. Wiley/Blackwell, Ames, pp 156-165

Turner NC, Molyneux N, Yang S, Xiong Y-C, Siddique KHM (2011) Climate change in south-west Australia and north-west China: challenges and opportunities for crop production. Crop Pasture Sci 62:445-456. doi:10.1071/CP10372

Wang J, Liu W, Dang T (2011) Responses of soil water balance and precipitation storage efficiency to increase fertilizer application in winter wheat. Plant Soil 347:41-51

Wang H, Zhou X, Wan C, Fu H, Zhang F, Ren J (2008) Eco-environmental degradation in the northeastern margin of the Qinghai-Tibetan Plateau and comprehensive ecological protection planning. Environ Geol 55:1135-1147. doi:10.1007/s00254-007-1061-7

Wang T, Wu J, Kou X, Oliver C, Mou P, Ge J (2010) Ecologically asynchronous agricultural practice erodes sustainability of the Loess Plateau of China. Ecol Appl 20:1126-1135. doi:10.1890/09-0229.1 
WMO (2005) Climate and land degradation. Publication No. 989, 32 pp. World Meteorology Office, Geneva, Switzerland. ISBN 92-63-10989-3.

Wu T, Schoenau J, Li F, Qian P, Malhi SS, Shi Y, Xue F (2004) Influence of cultivation and fertilization on total organic carbon and carbon fractions in soils from the Loess Plateau of China. Soil Tillage Res 77:59-68. doi:10.1016/j.still.2003.10.002

Xu B, Xu W, Huang J, Shan L, Li F-M (2011) Biomass production and relative competitiveness of $\mathrm{a}_{3}$ legume and a $\mathrm{C}_{4}$ grass co-dominant in the semiarid Loess Plateau of China. Plant Soil 347:25-39

Yamaguchi T (2011) Transition of mountain pastoralism: an agrodiversity analysis of the livestock population and herding strategies in southeast Tibet, China. Hum Ecol 39:141-154. doi:10.1007/s10745-010-9370-y
Yang SM, Malhi SS, Song JR, Xiong YC, Yue WY, Lu LL, Wang JG, Guo TW (2006) Crop yield, nitrogen uptake and nitrate-nitrogen accumulation in soil as affected by 23 annual applications of fertilizer and manure in the rainfed region of Northwestern China. Nutr Cycl Agroecosys 76:81-94. doi:org/10.1007/s10705-006-9042-x

Zhang J (2011) China's success in increasing per capita food production. J Exp Bot 62:3707-3711. doi:10.1093/jxb/err132

Zhang P, Yang J, Zhao L, Sarula B, Song B (2011) Effect of Caragana tibetica nebkhas on sand entrapment and fertile islands in steppe-desert ecotones on the Inner Mongolia Plateau, China. Plant Soil 347:79-90

Zheng D (1996) The system of physico-geographical regions of the Qinghai-Tibet (Xizang) Plateau. Sci China Ser D 39:410-417 (in Chinese with English abstract) 